\title{
COMERCIO Y COMERCIANTES DE PRODUCTOS COLONIALES EN GALICIA DURANTE EL MONOPOLIO CON AMERICA, 1765-1778
}

\author{
ISIDRO DUBERT \\ Universidad de Santiago de Compostela
}

\begin{abstract}
Resumen. En este trabajo atendemos a las transformaciones que experimentó la tradicional estructura comercial que existía en el noroeste de Galicia a consecuencia de los efectos generados, entre otros factores, por la habilitación del puerto de A Coruña para comerciar con América. Dichas transformaciones son abordadas durante la fase del monopolio (1765-1778), gracias a informaciones relativas a la entrada y descarga de coloniales en los muelles de la ciudad de los barcos correo. Asistimos así a la constitución de un mercado de géneros ultramarinos basado en la importación, en torno al cual nace y se desarrolla el embrión de una élite comercial, mayoritariamente foránea, en cuyo seno destacan en sobremanera no más de una docena de personas. En los márgenes de esa elite se situaban muchos pequeños y medianos compradores, entre los que sobresalían los integrantes de las tripulaciones de los citados barcos correo, una parte importante de ellos originarios del Señorío de Vizcaya. Un mercado que, asimismo, nos sitúa en el origen de las transformaciones que conoció alguno de los principales de ramos de la industria gallega de la época, caso, por ejemplo, de la vinculada al trabajo del cuero.
\end{abstract}

Palabras clave: coloniales, comercio, comerciantes, Galicia, América, siglo XVIII.

ABstract. This article research the transformations experienced by the traditional commercial structure that existed in Northwest of Galicia as result, among other factors, of the royal license

Recibido: 5-10-2018 • Aceptado: 12-11-2018 • isidro.dubert@usc.es

Trabajo realizado en el marco del proyecto de I+D, "La estructura de la ocupación y el ingreso en el largo plazo. Redefiniendo la modernización económica y los niveles de vida en Galicia, 1750-1975", Ministerio de Economía, Industria y Competitividad, (HAR2017-85601-C2-2-P). Agradezco a los evaluadores las consideraciones y orientaciones ofrecidas acerca del contenido del trabajo. 
to the port of A Corunna to trade with America. These transformations are studied during the Trade Monopoly Period with the Spanish colonies (1765-1778), thanks to information about the entry and unloading of overseas products (hides, sugar, cacao...) over in the wharves of the city. In this way, we can see the creation of a market of overseas products in A Corunna around which was born commercial elite, mostly foreign, within which a dozen people stood out. In the margins of those elite, there were many small and medium buyers, among which the members of the crews of mail boats stood out, an important part of them from Basque Country. A market of overseas products that places us, for instance in an industrial plane, at the origin of the transformations of leather Galician industry.

Key words: overseas products, commerce, merchants, Galicia, America, XVIII ${ }^{\text {th }}$ century.

\section{El comercio en Galicia antes del comercio con América}

Durante el siglo XVIII, Galicia fue una pieza clave en el comercio marítimo del norte de España. Por ejemplo, en los diez años anteriores a la habilitación de A Coruña para comerciar con América (1765), la introducción de mercancías a través de sus puertos generaba el 50-56\% del total de los aranceles cobrados por las aduanas de Cantabria, Asturias y la propia Galicia (Zabala Uriarte, 1986, p. 43; ID., 1983, vol. 2 , pp. 661-768). Unos ingresos procedentes en buena medida de la existencia de un intenso tráfico de cabotaje en sus costas, animado en parte por las élites locales de los gremios del mar, que en torno a 1750-1760 llegarían a conformar en el ámbito de las Rías Baixas una suerte de protoburguesía comercial (García Lombardero y Carmona, 1985, pp. 39-43; Dubert, 2008, pp. 228-229).

La mayor parte de este comercio marítimo se concentraba en la fachada atlántica de Galicia, dentro de la cual, y hasta la década de 1740, la mitad meridional fue mucho más activa y dinámica que la septentrional. Muestra de ello, es que en torno a esas fechas la villa de Pontevedra era, por su recaudación aduanera, el principal puerto de la zona sur y el segundo más importante del viejo reino, mientras que unos años antes, en 1734-1736, el pequeño puerto de Vigo superaba al de A Coruña en sus tratos con Inglaterra, además de mantener rutas comerciales abiertas con Andalucía y el Levante español (Zabala Uriarte, 1983, p. 295; González Fernández y Tizón Rodríguez, 2003, p. 73). Es más, durante la Guerra del Asiento (1739-1748), Vigo fue capaz de funcionar como base para un buen número de corsarios gallegos y franceses, estos últimos dotados de navíos más grandes y con una mayor capacidad ofensiva, mientras que en A Coruña tan sólo se armaron durante ese período dos barcos para «andar a corso» (Vázquez Lijó, 2017, pp. 122-125).

La situación cambió rápidamente a partir de mediados del siglo XVIII gracias a los efectos derivados, primero, de la creación del arsenal militar de Ferrol, y se- 
gundo, de la mencionada habilitación del puerto de A Coruña (Martín García, 2003, pp. 89-106; Alonso Álvarez, 1986, pp. 50-56). De hecho, la mayoría de los aranceles cobrados por las aduanas gallegas entre 1754 y 1765 son deudores de la actividad comercial desarrollada en ambos puertos por navíos vinculados a la construcción del citado arsenal. En relación con ella, por ejemplo, las autoridades locales informaban en 1749 a la Secretaría de Marina de que en A Coruña habían entrado ese año un total de veintisiete embarcaciones foráneas, trece de las cuales eran pataches y pinazas asturianas, cántabras y vizcaínas, de unas dieciséis toneladas de arqueo bruto, y siete eran urcas, pingues y galeotas holandesas, cargadas todas ellas con madera para Ferrol (Aragón Ruano, 2017, p. 43)².

Como puede verse, el grueso de este trasiego comercial se realizaba en barcos muy similares, sino de menores dimensiones, a los que conformaban la flota gallega de la época, que en esos mismos instantes traficaba con pescado, loza, vino, saín, aguardiente, sebo, tejidos, etc., en el cabotaje que tenía lugar entre en noroeste peninsular y los puertos situados en el arco que va de Lisboa al sur de Francia (Vázquez Lijó, 2016, pp. 93-96; Meijide Pardo, 1973, p. 803-807, y 818-822; Zabala Uriarte, 1983, vol.1, pp. 329 y ss.; Dubert, 2008, pp. 230-232)3. Un trasiego animado a su vez por los negociantes, mercaderes y factores asturianos, cántabros y vascos desplazados circunstancialmente hasta Galicia para cerrar tratos con las elites locales de los gremios del mar ${ }^{4}$. Este grupo de comerciantes era muy reducido, móvil y endogámico, además de residir de manera temporal en sus villas y ciudades costeras, donde no se avecindaban, aunque cuando lo hacían, no dudaban en invertir e intervenir en los arrendamientos municipales, la administración de las rentas del Estado, el abasto y la especulación de granos, la importación de productos de su tierra, etc. (Alonso Álvarez, 1977, p. 47-48; Meijide Pardo, 1984b). Una actividad esta última que desarrollaban aprovechando sus propias redes, construidas en la mayor parte de las ocasiones al margen de las de los gallegos, capaces de poner en contacto ámbitos geográficos y productivos del más variado cariz en su particular beneficio, el cual, y una vez instalados en Galicia, era empleado para conseguir su integración en el plano local como parte de las viejas elites sociales y políticas que dominaban el reino (González Fernández y Tizón Rodríguez, 2003, pp. 70-72; Meijide Pardo, 1967, pp. 96-98).

Archivo General de Simancas (en adelante AGS), Secretaría de Marina. Navegación de Particulares, leg. 503.

A.G.S., Estado, leg. 7361.

Caso, por ejemplo, de los «... muchos mercaderes de Asturias y de las cuatro villas de la Encartación de Vizcaya que estaban presentes...» en las ventas de pescado realizadas en noviembre de 1714 en la villa de Ares, Archivo del Reino de Galicia (en adelante ARG), Real Audiencia, leg. 25204-41, pp. 141 y ss. 
En la misma línea, sabemos que entre 1717 y 1765 algo más de la mitad de las arribadas forzosas de la flota de Indias a la península Ibérica se produjeron en las costas gallegas, cuyos navíos acababan en dos de cada tres ocasiones fondeados en las ensenadas de A Coruña y Ferrol, donde en torno a la década de 1740 es posible detectar la conformación de una infraestructura comercial de mayor fuste, si bien mucho más reducida en número, que la que operaba en el cabotaje. En su base se situaban los vicecónsules de Francia e Inglaterra, atendiendo a los barcos de sus respectos países, y agentes de comercio llegados de Cádiz con la intención de controlar los desembarcos de plata y coloniales de los navíos fletados por los mercaderes gaditanos en Indias (García-Baquero, 1988, vol. 2, pp. 112-118, y pp. 154-155). La importancia de estos desembarcos no parece haber sido desdeñable, visto que entre 1743 y 1749 constituyeron el $61-62 \%$ del total de las arribadas de metales preciosos a la península. Además, su recepción y descarga, como su posterior traslado por tierra a Castilla, era dirigido por los mencionados vicecónsules extranjeros y agentes gaditanos, a los que pronto se sumaron algunos de los principales comerciantes foráneos asentados en A Coruña, quienes por esta vía comenzaron a involucrarse en una intermediación financiera básica, cierto que periférica y escasa, pero estructuralmente relevante a medio y largo plazo (Cebreiro Ares, 2017, pp. 269-286).

Pese a todo, apenas tres años después del inicio de las obras de construcción del arsenal de Ferrol, en 1752, las fuentes de la época obvian esta serie de cambios. El Catastro de Ensenada, por ejemplo, nos indica que el comercio de la ciudad de A Coruña se caracterizaba por su composición heterogénea y por gozar de una clara diferenciación funcional, una fuerte jerarquización interna y una relativa presencia de mujeres en su seno (Tabla 1). En definitiva, por ser tradicional y estar compuesto por unas 209 personas - situadas al frente de aproximadamente el 10\% de los hogares de la ciudad-, de las que un 39\% eran mujeres, muy numerosas en el ramo de la venta de fruta, pescado y vino al por menor. Solo un 7\% de sus integrantes, para entendernos, quince individuos, realizaban operaciones comerciales de una cierta envergadura, las cuales rendían utilidades medias de 14.000 reales, aunque lo habitual era que lo ganado con estas operaciones se dispusiese entre los 3.000 y los 32.000 reales, en buena medida gracias a que «los mercaderes de paños, vinos y otros efectos, libran cantidades y fijan letras a proporción de sus caudales, con el lucro e interés de su comercio, según las plazas y lugares para donde libran [...], en que se incluye el interés del giro de letras $\iota^{5}$. Salvando las distancias, un mundo este muy parecido al que puede encontrarse en Vigo por las mismas fechas, donde el comercio local demuestra ser también tradicional en su composición, forma y modo de operar (González Fernández y Tizón Rodríguez, 2003, pp. 81-82).

ARG, Serie Catastro de Ensenada, Interrogatorio, pregunta n ${ }^{\circ} 31$, leg. 46278/12-2 ( $\left.{ }^{\circ} 874\right)$. 
Tabla 1. Composición del mundo del comercio en los puertos de A Coruña y Vigo a mediados del siglo XVIII

\section{A) A Coruña}

\begin{tabular}{|l|c|c|c|c|c|}
\hline Categoría & $\begin{array}{c}\text { \% Gentes del } \\
\text { comercio }\end{array}$ & $\begin{array}{c}\text { \% de } \\
\text { Mujeres }\end{array}$ & $\begin{array}{c}\text { Utilidad } \\
\text { media }\end{array}$ & $\begin{array}{c}\text { Utilidad } \\
\text { máxima }\end{array}$ & $\begin{array}{c}\text { Utilidad } \\
\text { mínima }\end{array}$ \\
\hline Negociantes y mercaderes & 7 & 13 & 14.403 & 32.000 & 3.000 \\
\hline Mercaderes de vino & 9 & 0 & 5.263 & 30.500 & 1.500 \\
\hline Tenderos y merceros & 39 & 17 & 3.313 & 11.365 & 547 \\
\hline Tratantes de pescado & 8 & 82 & 1.603 & 12.100 & 730 \\
\hline Tratantes de feiras y mercados & 15 & 53 & 1.060 & 3.000 & 730 \\
\hline Fruteros & 11 & 83 & 820 & 1.800 & 730 \\
\hline Taberneros de medio real al día & 11 & 68 & 182 & 182 & 182 \\
\hline TOTAL & 100 & 39 & 3.191 & 32.000 & 182 \\
\hline Número de casos & 209 & 82 & cantidades en reales de vellón & & \\
\hline
\end{tabular}

B) Vigo

\begin{tabular}{|l|c|c|c|c|}
\hline Categoría & $\begin{array}{c}\% \text { Gentes del } \\
\text { comercio }\end{array}$ & Utilidad media & $\begin{array}{c}\text { Utilidad } \\
\text { máxima }\end{array}$ & $\begin{array}{c}\text { Utilidad } \\
\text { mínima }\end{array}$ \\
\hline Mercaderes & 10 & 7.200 & 11.500 & 5.000 \\
\hline Comisionistas-Tratantes & 3 & 2.200 & & \\
\hline Vicecónsules & 2 & 2.200 & & \\
\hline Tenderos & 43 & 600 & 2.000 & 50 \\
\hline Tenderos de vereda & 3 & 450 & 200 & 200 \\
\hline Traficantes de pescado & 5 & 200 & 150 & 150 \\
\hline Revendedoras de sardina & 31 & 150 & & \\
\hline No consta & 3 & & & \\
\hline TOTAL & 100 & & & \\
\hline Número de casos & 62 & cantidades en reales de vellón & & \\
\hline
\end{tabular}

Fuente: Para A Coruña, ARG, Serie Catastro de Ensenada, A Coruña, leg. 46278 ( $\left.n^{\circ} 875\right)$, elaboración propia. Para Vigo, véase González Fernández y Tizón Rodríguez, 2003, p. 80.

Es evidente, pues, que a mediados del siglo XVIII el Catastro está lejos de dar cuenta de una manera completa y exhaustiva de la realidad del comercio coruñés. Sin ir más lejos, no aparecen recogidos en él los nombres de los vicecónsules extranjeros, ni los de los tratantes asturianos, cántabros o vascos que sabemos residían circunstancialmente en la ciudad y operaban en ella, o en sus inmediaciones, merced al cabotaje realizado con el norte de España. Igualmente, tampoco aparecen en la fuente los nombres de los comerciantes que, y al poco de instalarse en la urbe - como, por ejemplo, Jerónimo Hijosa, que lo hizo en 1751- se encontraban trabajando ya en 1752 en la compra e importación de enormes partidas de grano desde Santander, Vizcaya o el sur Francia, con la intención de avituallar a los habitantes de A Coruña, Ferrol y las poblaciones colindantes (Meijide Pardo, 1967, pp. 90-91). Del mismo modo, el Interrogatorio del mencionado Catastro nada nos dirá sobre las entradas y salidas en el puerto coruñés de los navíos que alimentaban su comercio de cabotaje, 
o el específicamente peninsular y europeo. Al respecto, todo se reduce a realizar una mera descripción de una parte de su flota de pesca ${ }^{6}$.

No tener presente esta serie de ocultaciones, como no tener presentes los efectos generados por las arribadas forzosas de barcos llegados de Indias cargados de metales preciosos, o por la construcción del arsenal de Ferrol, podría llevarnos a pensar que la habilitación de A Coruña en 1765 fue un epifenómeno, el acontecimiento que habría dado lugar al nacimiento exnovo en el noroeste de Galicia de una estructura comercial vinculada a los tráficos ultramarinos, lo que no fue el caso. Lo cierto, es que, a este nivel, la mencionada habilitación incidía sobre una estructura comercial preexistente, la cual, al menos desde comienzos de la década de 1740, se hallaba inmersa en una lenta pero inexorable mutación, sobre todo en su cúspide. Prueba de ello, es por ejemplo la llegada e instalación en A Coruña de mercaderes - como el mencionado Jerónimo Hijosa-, desembarcados en la ciudad al calor de las oportunidades de negocio que ahora ofrecían las obras del arsenal ferrolano. Al objeto de aprovecharlas fue que estos últimos no dejaron de llegar y asentarse en el enclave tras 1751-1752. Sin ir más lejos, así lo hicieron el asturiano Ramón Fernández Barca y el palentino Manuel Díaz Tabanera en 1760, el riojano Manuel del Cerro Rubio en 1761 o, y a lo largo de la década de 1760, hasta una veintena de individuos de nacionalidad francesa dedicados mayoritariamente al comercio, quienes en los años venideros trabajarían como agentes para firmas comerciales instaladas en Burdeos y Bayona introduciendo mercancías foráneas (García López, 2008, pp. 218, 231, 234; Meijide Pardo, 1976, p. 207).

Es desde este punto de partida que Galicia, que nunca había quedado al margen de los grandes tráficos comerciales peninsulares y europeos, ni de las transformaciones económicas y sociales que éstos animaron en el plano local, se incorporará a los beneficios generados por el comercio ultramarino en 1765 (Ferreira Priegue, 1988 y 2000; Juega Puig, 2014; Meijide Pardo, 1973; García Lombardero y Carmona, 1985; Dubert, 2008; Alonso Álvarez, 1986). Una incorporación que, y a semejanza de como ocurría en otras ciudades del norte peninsular cantábrico, caso de Santander, fue posible gracias a la existencia de esa estructura comercial previa a la que nos hemos referido, la cual aprovecharía los intereses geoestratégicos de la corona en el Atlántico para desarrollarse (Lanza García, 2006, pp. 423-426). Basta con atender a lo que para ella supuso la construcción del arsenal, la mejora de la red viaria gallega y de las comunicaciones con la meseta o la posibilidad de emplear la flota de barcos correo para garantizar las

Compuesta por un patache de 50 toneladas, dos traíñas, diez lanchas y siete botes, ARG, Serie Catastro de Ensenada, Interrogatorio de A Coruña, pregunta $n^{\circ} 37$, leg. 46278/12-2 (n $\left.{ }^{\circ} 874\right)$. Para hacernos una idea de las omisiones en las entradas y salidas en puerto, véase por ejemplo el contenido del informe mencionado en la nota $\mathrm{n}^{\circ} 2$, AGS, Secretaría de Marina. Navegación de Particulares, leg. 503 
rutas marítimas, hacer frente a posibles agresiones británicas o entorpecer las relaciones entre Inglaterra y Portugal. Aunque esa estructura también medró y evolucionó merced a los particulares intereses económicos de la monarquía, visto el deseo de ésta de ver incrementados los ingresos de la Real Hacienda gracias a los beneficios que confiaba iba a generar el comercio con Indias a través de los puertos habilitados.

\section{La fuente y sus limitaciones}

Las aduanas de A Coruña llevaban a cabo un relativo control de las entradas de barcos y mercancías en puerto. De los registros de todas y cada una de esas entradas entre 1767 y 1781, y lo que es más importante, de los compradores individuales de esas mercancías, de la procedencia de éstas y de las cantidades que adquirieron y para quien, tenemos noticia gracias a la copia que de esos registros realizó en 1782 don Antonio Ocampo, oficial de la Contaduría de Rentas Generales del Reino de Galicia. Fue él quien se encargó, a instancias de un grupo de mercaderes de la ciudad, de elaborar durante todo ese año una relación única de las llegadas de los navíos y de las compras que los particulares hicieron de los distintos productos que éstos traían. De este modo, Ocampo daba «noticia de todos los géneros venidos de los puertos de Inglaterra, Francia, Holanda, y otros [lugares], como de los cueros y azúcares que se introdujeron en este [puerto por]... los [correos] habilitados de América, con distinción de sus respectivos interesados y consignaciones sujetos a la paga de portazgo, desde el año de 1768 hasta el de 1781, ambos inclusive» ${ }^{7}$.

El objetivo de esta relación era poder prorratear entre todos los comerciantes habían participado en el comercio marítimo de cabotaje, así como en el peninsular, europeo y americano, los gastos que en su día les generó el seguimiento de los pleitos que habían tenido con la Real Hacienda y el concejo coruñés sobre el pago de los derechos de peso y portazgo por las mercancías descargadas en puerto entre $1768 \mathrm{y}$ 1781. Ambos pleitos se habían seguido, uno, en el Consejo de Castilla, y otro, en la Real Audiencia de Galicia, en este último caso entre las gentes del comercio local y los arrendatarios del portazgo, quienes en todo momento contaron con el respaldo de las autoridades municipales, lógicamente, parte interesada en el conflicto. El impago de la relación elaborada por don Antonio Ocampo, hizo que éste denunciase en 1787 a quienes le habían encargado el trabajo, primero, ante el Real Consulado de A Coruña, y luego, ante la Real Audiencia, donde se incluyó una copia parcial de la misma correspondiente a los años 1768-1773 y 1779-1781 entre los autos judiciales ${ }^{8}$.

ARG, Real Audiencia, leg. 25451-29, $1^{\mathrm{a}}$ pieza.

ARG, Real Audiencia, leg. 25451-29, $3^{\text {a }}$ pieza. 
La fuente, de cuya existencia y posibilidades advirtió en su día Antonio Meijide Pardo (1984, p. 102), nos permite acercarnos tras un laborioso proceso de reconstrucción a partir de la información contenida en los distintos registros individuales, a los flujos del comercio de los distintos productos, a la estructura y peso de las remesas importadas, a la configuración del mercado de esos productos, a la personalidad comercial y social de los compradores, a su modus operandi o al volumen de sus transacciones, durante la fase de esplendor del comercio americano desarrollado a través del puerto de A Coruña, la menos estudiada y también la menos conocida, lo que otorga un franco valor a los resultados obtenidos en el curso de esta investigación (Alonso Álvarez, 1986, pp. 54 y ss.). Para aproximarnos a esta serie de cuestiones, haremos uso de los registros individuales correspondientes a los años 1768-1773 y 1779, ya que todo apunta a que los efectos de la entrada en vigor de los Decretos de Libre Comercio de 1778 no afectaron a la importación de productos ultramarinos hasta finales de 1779 , esto es, hasta poco después del inicio de la guerra con Inglaterra, en junio de 1779.

Sin embargo, pese a la suerte que supone poder contar con esta relación sistemática de registros individuales, la fuente es limitada, pues para las mercancías solo consigna la arribada y peso de los coloniales que los buques traían consigo. Es decir que, y en el caso del comercio americano, del que ahora nos ocupamos, ignoramos tanto las posibles ocultaciones por fraude como lo que dichos coloniales supusieron en el valor total de las importaciones realizadas desde el Nuevo Mundo. De ellas, sabemos que los metales preciosos, aun sin poder determinar su porcentaje exacto ni en volumen ni en valor económico, eran el producto estrella. Para que nos hagamos una idea, en los años que siguieron a la aparición de los Decretos del Libre Comercio, esto es, entre 1778 y 1816 , el oro $(20,8 \%$ ) y la plata $(70,9 \%)$ constituyeron el $91,3 \%$ del valor total de las importaciones americanas llegadas al puerto de A Coruña —en el 90,3\% de las ocasiones procedentes del Rio de la Plata-, y de ese valor apenas si se quedó en Galicia el 26,8\% del total (Alonso Álvarez, 1991, pp. 469-473). Nada de esto se sabe para la época del monopolio, aunque podemos suponer que la cosa no debería de haber cambiado demasiado con respecto a lo ocurrido tras 1778 . Sea como fuere, lo cierto es que a día de hoy todavía ignoramos lo que las partidas de metales preciosos suponían en el valor total de las importaciones procedentes del Nuevo Mundo, y por tanto, la importancia que en ellas habrían tenido los coloniales ${ }^{9}$. A propósito de

$9 \quad$ Por ejemplo, las autoridades de marina locales informan a la Secretaría de Marina de que catorce de las quince arribadas de navíos registradas en 1769 en A Coruña fueron barcos correo, los cuales trajeron en su bodegas un total de 603.940 reales de la Real Hacienda, 874.620 reales de la Renta del Correo, 1.717.980 de reales de particulares, 18.047 cueros al pelo, 1,5 toneladas de lana de vicuña, medio quintal de café, 326 kilogramos de tabaco, 51 pieles de tigre y otras muchas mercancías. A.G.S., Secretaría de Marina. Navegación de Particulares, leg. 510-1. Sin embargo, el margen de ocultación, o de imprecisión, de estos informes es muy elevado, visto que los datos de la relación 
ello, podríamos realizar una aproximación grosera, un cálculo que, evidentemente, carecería valor histórico, pero que cuando menos nos ayudaría a hacernos una idea aproximada de la relevancia que habrían podido tener esos coloniales en los tráficos ultramarinos del momento.

Pero antes de avanzar en esta dirección, es conveniente aclarar al lector que no nos ha sido posible encontrar los precios de mercado de los géneros desembarcados en el puerto coruñés en 1765-1778, por lo que se ha procedido a estimar su valor a partir de los precios registrados en Cádiz a comienzos de octubre de $1792^{10}$. Gracias a ellos, hemos calculado el valor total de la carga de coloniales traída por los barcos correos en 1768-1773 y 1779 (Tabla 2). Esto significa que en esa estimación grosera que proponemos, se ha partido del supuesto de que los precios de 1792 - y por tanto el valor de la carga estimada - ni habrían subido en exceso ni se habrían visto afectados en sobremanera por la inflación desde 1768-1779.

$\mathrm{Si}$ aceptamos estas premisas, bastaría entonces con poner en relación el valor de los principales productos llegados a puerto desde Buenos Aires y Montevideo en 1768-1779 — cueros, lana de vicuña y pimienta tabasco — , con el valor de las exportaciones realizadas desde A Coruña al Río de la Plata en esos mismos años (Tabla 2). Advertimos entonces que el valor de las importaciones en 1768-1773 sería el equivalente a un $35,8 \%$ del valor de las exportaciones, mientras que, y sumando años sueltos, en 1768-1779 dicho valor sería más elevado, un 45,7\%. Asimismo, advertimos también que el valor de las importaciones habría tendido a crecer entre 1768 y 1771, llegando a situarse en 1771 en un 62,1\%, para luego caer. Igualmente, en 1779 ese valor sería ya 3,7 veces más elevado que el de las exportaciones realizadas ese mismo año desde A Coruña.

Aunque estos porcentajes y las tendencias que definen deben contemplarse con la natural prevención, lo cierto es que, a priori, se orientan en la misma dirección que algunas de las claves que contribuyen a dar forma y sentido al contexto histórico de la época. Por ejemplo, el creciente valor de las importaciones de coloniales se explicaría por el hecho de que el grueso de las exportaciones de A Coruña a Buenos Aires y Montevideo estaba compuesto en el 94\% de las ocasiones por textiles de procedencia peninsular, un 44\% de los cuales se elaboraban en Galicia y el resto en Asturias, la montaña cántabra, la Rioja, el norte de Castilla y Cataluña (Alonso Álvarez, 2011, p. 47). Curiosamente, y como luego veremos, en los mismos ámbitos geográficos de

que manejamos indican que en 1769 se desembarcaron en la ciudad un total aproximado de 44.125 cueros al pelo, de los que un 2,2\% estaban «averiados».

10 Publicados en El correo mercantil de España y sus Indias, número correspondiente al 11 de octubre de 1792, pp. 33-35. Consulta en http://hemerotecadigital.bne.es/issue.vm?id=0003196174\&search $=\&$ lang=es, el 13 de septiembre de 2018 . 
Tabla 2. Valor aproximado de las importaciones de coloniales realizadas desde el Río de la Plata con respecto al valor de las exportaciones efectuadas a la zona desde A Coruña, 1768-1779

\begin{tabular}{|c|c|c|c|}
\hline Años & $\begin{array}{c}\text { Valor de los } \\
\text { coloniales importados }\end{array}$ & $\begin{array}{c}\text { Valor de las exportaciones } \\
\text { al Río de la Plata }\end{array}$ & $\begin{array}{c}\text { Importaciones con respeto a las } \\
\text { exportaciones (en \%) }\end{array}$ \\
\hline 1768 & 1.154 .688 & 9.120 .000 & 12,7 \\
\hline 1769 & 2.273 .995 & 8.922 .000 & 25,5 \\
\hline 1770 & 3.368 .180 & 8.749 .000 & 38,5 \\
\hline 1771 & 4.426 .763 & 7.129 .000 & 62,1 \\
\hline 1772 & 3.380 .002 & 7.597 .000 & 39,5 \\
\hline 1773 & 2.973 .011 & 7.580 .000 & \\
\hline 1779 & & & \\
\hline & 5.555 .699 & 1.489 .000 & 35,8 \\
\hline $1768-1773$ & & & 45,7 \\
\hline $1768-1779$ & 17.594 .639 & 49.097 .000 & \\
\hline
\end{tabular}

Fuente: ARG, Real Audiencia, leg. 25451-29, elaboración propia. Para el valor de las exportaciones desde A Coruña, Alonso Álvarez, 1986, p. 54.

los que procedían los principales mercaderes involucrados en el comercio con América (Tablas 5 y 6). En la misma línea, la caída del valor de las exportaciones en 1779 con respecto a lo sucedido en los años anteriores, debió mucho a los efectos de la guerra de España con Inglaterra (1779-1783).

En suma, y aun desconociendo el monto y el peso total que tuvieron los productos coloniales en el conjunto de las importaciones americanas realizadas en 1768-1779 por el puerto de A Coruña, todo apunta a su enorme relevancia. En consecuencia, nada nos impide utilizar los registros individuales consignados en la fuente para profundizar en la naturaleza de ese tráfico comercial y sus implicaciones en la Galicia del Antiguo Régimen.

\section{Comercio y comerciantes de coloniales en Galicia}

El Real Decreto de 1765 habilitaba al puerto de A Coruña para comerciar en régimen de monopolio con Cuba, Santo Domingo, Puerto Rico, Trinidad y Margarita. En los años siguientes esa habilitación se ampliaría al Río de la Plata, Nueva España y otros territorios americanos (Mapa 1). Estos tráficos pivotaban sobre la navegación de los correos marítimos, es decir, sobre un sistema de transporte rápido, seguro y propiedad de la corona, que asumía todos sus costes (Belloto, 1971, pp. 93-107; Alonso Álvarez, 1986, pp. 49-51; ID., 2011, pp. 39-46). Gracias a esta fórmula, que supuso un $15 \%$ de las entradas de barcos en puerto entre 1768 y 1779, Galicia pasó a integrarse en los flujos ultramarinos, cuya principal virtud fue la de impactar con fuerza y dar lugar a la rápida transformación de la estructura comercial que existía en el noroeste de Galicia, la cual, se hallaba sometida desde los inicios de la década de 1740 a un lento y paulatino cambio. 


\section{Mapa 1. Derrota de los barcos correo}

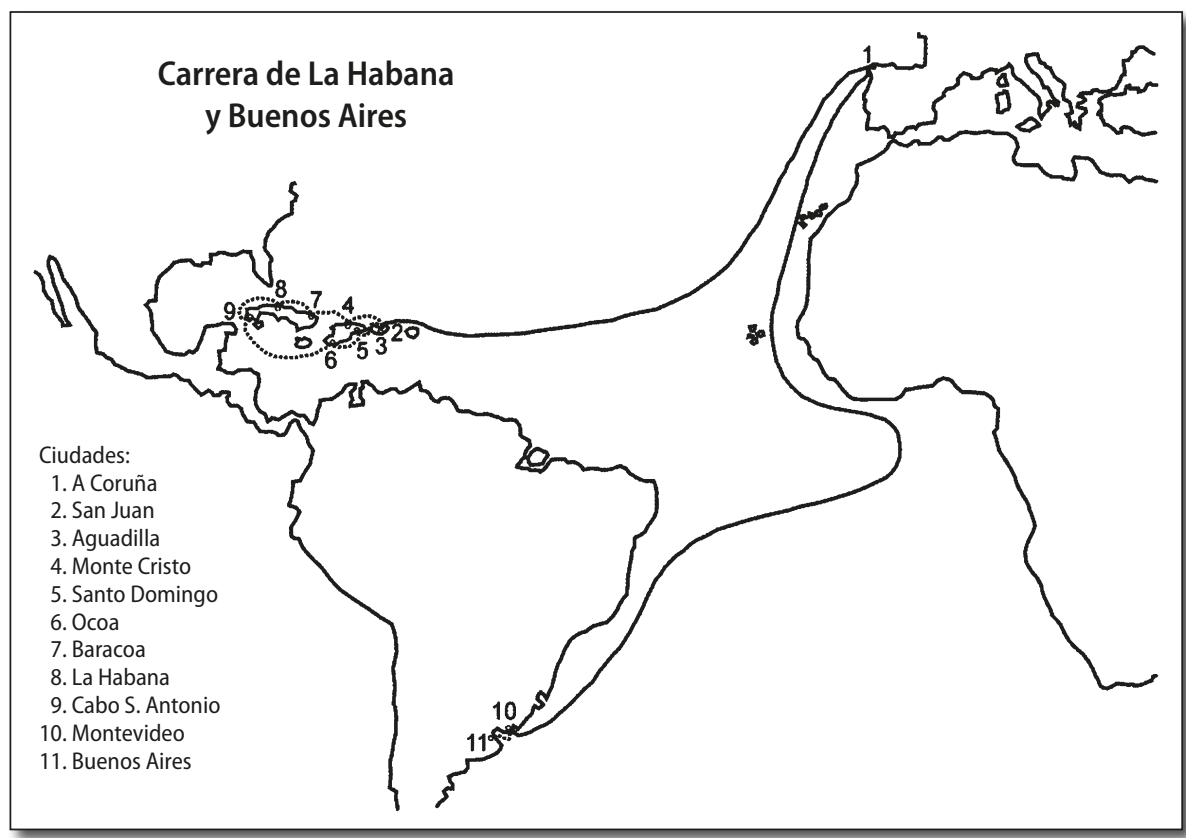

Fuente: Belloto (1971), p. 105.

Un buen ejemplo de las implicaciones de ese impacto lo tenemos en lo acontecido en la base de esa estructura comercial. La apertura de A Coruña al tráfico con Río de la Plata en 1767 hizo que el comercio de cabotaje del norte de España redefiniese su vieja lógica de funcionamiento. Frente a la tradicional intensidad que tenía el flujo de embarcaciones oeste-este, de Galicia al País Vasco, ganó peso ahora uno en sentido contrario, del País Vasco a Galicia, que se mantuvo muy activo hasta 1778-1779. Luego vendría su posterior reversión en dirección al este. Fue entonces cuando se hizo evidente que la época del monopolio en Galicia había sido la etapa más rentable y de mayor desarrollo del cabotaje vizcaíno (Zabala Uriarte, 1991, p. 336). Prueba de ello, es que $26 \%$, de todos los barcos que atracaron en la ensenada coruñesa entre 1768 y 1779 eran navíos vascos, llegados a la ciudad cargados con utensilios, balaustres y barras de hierro, harina, grasa de cerdo, brea, lienzos, jarcias, baquetas y otros productos que mudaban en el tornaviaje por cueros rioplatenses, azúcar cubano y caudales americanos. Más aún, si tres años después del permiso otorgado a la ciudad para comerciar con Río de la Plata, en 1770, esos navíos eran un 11\% del total de 
los entrados en puerto, en 1771 este porcentaje se situaba ya en el 28\%, en 1772 en el $30 \% \mathrm{y}$, andando el tiempo, en 1779 , en el $65 \%{ }^{11}$. Un año este último que coincide con la llegada de Río de la Plata de 105.815 cueros al pelo y la aparición de la Real Orden que gravaba fiscalmente su introducción en las Provincias Exentas (Gráfico 1).

En la misma línea, el comercio americano también aceleró la redefinición en la que se hallaba sumido el sistema portuario gallego a mediados del siglo XVIII, y que a partir de 1765 funcionaría en beneficio de A Coruña. De hecho, los aranceles cobrados por las aduanas de la ciudad en 1763-1764 pasaron de ser el 27,1\% del total de los recaudados en los distintos puertos de Galicia, a un 46,8\% en 1765-1769 y a un 52,7\% en 1768-1778 (Zabala Uriarte, 1986, p. 47 y 52). Un crecimiento que fue de la mano del registrado por el número de embarcaciones, de cabotaje o no, que atracaron en la rada coruñesa: 417 en 1768-1772, y 677 en 1785-178912. En este caso, sin embargo, y a diferencia de lo que sucedía en las Rías Baixas, donde el comercio de pescado con Portugal estimulaba el nacimiento de una auténtica protoburguesía autóctona, todavía hoy desconocemos cuáles fueron a este nivel los efectos que la intensificación del cabotaje gallego hacia País Vasco tuvo sobre las villas marineras situadas al norte de la ría de Arousa (García Lombardero y Carmona, 1985, pp. 39-43; Dubert, 2008, pp. 228-230).

Al margen de las remesas de plata y oro, buena parte de estas transformaciones fueron posibles gracias a la continua arribada a puerto de lo que, no obstante, demuestra haber sido una gama de mercancías muy limitada. Básicamente cueros, procedentes de Buenos Aires y Montevideo, y azúcar, traído de Cuba. Dos partidas que supusieron el 94,6\% del valor total de los tratos cerrados en los años para los que disponemos de información (Tabla 3). Fuera de ellas, un exiguo y anecdótico 5,4\% de ese valor corresponde a la descarga de lana de vicuña, cacao, café, pimienta tabasco o palo Campeche. Esto nos advierte de que el comercio de importación de Indias, en general, y el de coloniales, en particular, se caracterizó durante la fase del monopolio por su escaso grado de diversificación y un elevado grado de concentración en apenas unos pocos productos, lo cual, en realidad, era algo que se propiciaba en los mismos

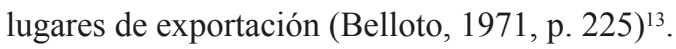

\footnotetext{
$11 \quad$ ARG, Real Audiencia, leg. 25451-29, $3^{\mathrm{a}}$ pieza.

12 Para 1768-1772, datos extraídos del ARG, Real Audiencia, leg. 25451-29, $3^{\text {a }}$ pieza; para 1785-1789, véase Meijide Pardo, 1984a, p. 89.

13 Junto a los productos especificados en la tabla, también llegaron en esa época a A Coruña 12,7 toneladas de sebo moreno, 1,03 toneladas de cera y alrededor de unos 300.000 litros de aguardiente. Géneros que no se han incluido en los cómputos por no haber conseguido averiguar sus respectivos precios. En todo caso, estimamos que su ausencia de la mencionada tabla no altera en mayor medida el contenido básico de la misma.
} 
Tabla 3. Productos coloniales llegados al puerto de A Coruña, 1768-1779

\begin{tabular}{|l|c|c|c|c|c|}
\hline Géneros & \multicolumn{2}{|c|}{ Cantidad } & $\begin{array}{c}\text { Precio } \\
\text { en reales }{ }^{[1]}\end{array}$ & $\%$ & $\begin{array}{c}\text { Procedencia } \\
\text { de la carga }\end{array}$ \\
\hline Cueros & 408.024 & Unidades & 21.298 .853 & 50,4 & Río de la Plata \\
\hline Azúcar & 5.370 & Tm. & 18.677 .808 & 44,2 & La Habana \\
\hline Lana vicuña & 30 & Tm. & 1.823 .360 & 4,3 & Río de la Plata \\
\hline Cacao & 23 & Tm. & 284.149 & 0,7 & Guayaquil, Caracas, Magdalena \\
\hline Café & 0,1 & Tm. & 1.000 & 0,0 & Guayaquil, Caracas, Magdalena \\
\hline Pimienta tabasco & 1,6 & Tm. & 10.125 & 0,0 & \\
\hline Palo campeche & 127 & Tm. & 172.375 & 0,4 & Guayaquil, Caracas, Magdalena \\
\hline Total & 5.551 & Tm. & 42.267 .670 & 100 & \\
\hline
\end{tabular}

[1] Precios tomados de El correo mercantil de España y sus Indias, número correspondiente al 11 de octubre de 1792, pp. 33-35. Consulta en http://hemerotecadigital.bne.es/issue.vm?id=0003196174\&search=\&lang=es, el 13 de septiembre de 2018.

Fuente: ARG, Real Audiencia, leg. 25451-29. Elaboración propia.

La llegada de cueros al pelo a los muelles de A Coruña estuvo garantizada no solo por la existencia de un sistema de transporte rápido y seguro, como los correos marítimos, sino también, y entre otras cosas, porque en la ciudad Buenos Aires, uno de los principales centros de aprovisionamiento de esta materia prima, se pusieron en funcionamiento en esos años nuevos mataderos, coincidiendo tanto con su imparable aumento demográfico como con la creciente demanda de la misma por los mercaderes peninsulares (Cuesta, 2007, pp. 32 y 41).

Los escasos datos fragmentarios referidos a los cueros desembarcados por los barcos correos en A Coruña aparecen recogidos en el gráfico 1, donde se aprecia la paulatina subida que experimentó su número desde 1768, hasta estabilizarse en torno a unas 60.000 unidades al año tras 1770, para superar luego, en 1779, las 105.000. Con posterioridad a esta fecha se hacen evidentes en este tráfico comercial los efectos negativos de la guerra con Inglaterra (1778-1783), la entrada en vigor de los Decretos del Libre Comercio en 1778 y la participación de Vigo en la carrera de Indias (Dubert, 2009, pp. 386-390), todo lo cual, no impidió sin embargo la posterior recuperación de las importaciones de cueros a los niveles de los años setenta, tal y como como nos lo indica que A Coruña recibiese en 1793-1796 una media aproximada de 74.000 unidades al año (Silva, 1993, p. 83). Este flujo se vería cortado por una nueva guerra con Inglaterra (1796-1801), con todo, menos lesiva para este comercio que el enfrentamiento anterior, a pesar de haber contado con la participación en el mismo de los barcos correo, visto que en 1802-1804 entraban en el puerto coruñés una media de 93.147 unidades al año (Silva, 1993, p. 112).

Todo apunta pues a que A Coruña mantuvo una posición de privilegio en el comercio de cueros al pelo realizado desde el norte de la península, una parte significativa de los cuales era exportada luego hacia los puertos asturianos, cántabros, vascos y del 
sur de Francia, desde donde era reexportada a otros lugares (Carmona, 2003, pp. 24 y 29). En este sentido, ni siquiera el auge comercial que experimentó la ciudad de Santander al remate de la primera guerra con Inglaterra (1778-1783), supuso una grave competencia para la hegemonía coruñesa (Lanza García, 2006, p. 426). Así nos los indica, por ejemplo, que el puerto cántabro recibiese de Rio de la Plata en 1793-1793 una media anual de 62.115 cueros al pelo y en 1802-1804 de 83.976, en ambos casos, cantidades inferiores a las registradas por la aduana coruñesa en las mismas fechas (Silva, 1993, pp. 89 y 112).

\section{Gráfico 1. Unidades de cueros al pelo desembarcadas en A Coruña por los barcos correo, 1768-1804}

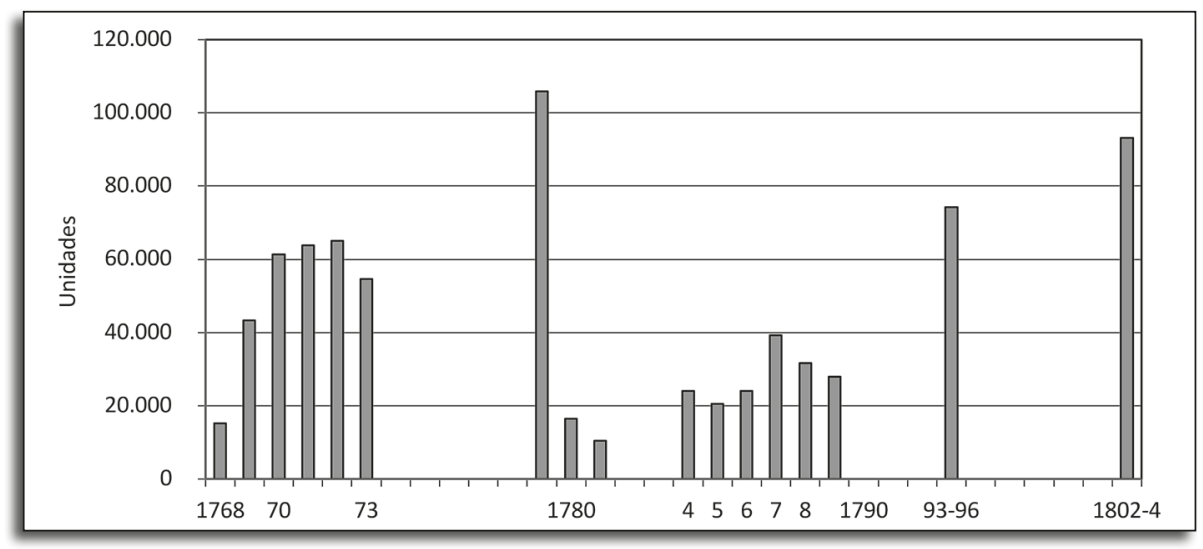

Fuente: Para 1768-1781, ARG, Real Audiencia, leg. 25451-29, 3a pieza, elaboración propia. Para 1784-1778, Meijide Pardo, 1984a, p. 102, para 1793-6 y 1802-4, Silva, 1993, pp. 83 y 112.

Desde 1767, una parte de los cueros llegados a Coruña permanecía en Galicia para alimentar a la industria del curtido local. En los inicios de la década de 1770 su abundancia dio lugar a una serie de importantes transformaciones en la misma, al propiciar, entre otras cosas, la concentración en un único punto de todas las fases de la producción, la cual era vendida más tarde por el empresario en diferentes mercados, contando muchas veces con la ayuda de transportistas maragatos (Carmona, 2003, pp. 29-31; ID., 1990, p. 89-90; Rubio Pérez, 1995, pp. 245-246). En el marco de este proceso de cambio productivo, la entrada en vigor de la Real Orden de 1779 que, recordemos, gravaba la exportación de cueros desde los territorios de la Corona de Castilla a las Provincias Exentas, desembocó en la apertura y en la relocalización de muchas tenerías vascas en los territorios vecinos, como Cantabria o el sur de Francia, pero también en otros puntos más lejanos, como Galicia. Algo que en este último caso 
fue posible gracias a la combinación de las posibilidades que ofrecía la Real Cédula de 1781, que concedía exenciones y franquicias a la apertura nuevas fábricas de curtidos, el incremento de las actividades industriales del arsenal de Ferrol y el fácil acceso a una abundante materia prima (Carmona, 2003, pp. 30-32). En este contexto se produjo la llegada y asentamiento en Galicia de maestros curtidores vascos y, en menor medida, de catalanes, quienes a partir de mediados de la década de 1780 procedieron a abrir nuevas tenerías en las inmediaciones de Betanzos, Pontedeume, Santiago y otros puntos del territorio gallego. Tras la guerra contra el francés (1808-1814), el sector siguió creciendo, al punto de que a mediados del siglo XIX un tercio de las productos de cuero consumidos en España estaban elaborados en Galicia, donde se ubicaban tan solo un 7\% de las fábricas existentes en la península (Carmona, 2003, pp. 29-34). Como se desprende de lo dicho, este control del mercado estatal del cuero no se entiende sin los cambios que conocieron esas fábricas, los cuales, en origen, estuvieron propiciados por el continuo desembarco en Galicia de cueros al pelo rioplatenses.

Por su parte, la llegada de azúcar al puerto de A Coruña fue posible gracias a las nuevas condiciones que se dieron en Cuba tras la invasión inglesa de 1762-1763. La introducción de mano de obra esclava y la creación de nuevos ingenios azucareros, junto a la mayor presión de la demanda y el alza de precios que siguió a la posterior recuperación de la isla por España, la convertirían en uno de los grandes productores mundiales de la época (Moreno Fraginals, 2001, pp. 27-36).

De manera parecida a como sucedía con los cueros, A Coruña consiguió mantenerse como el principal puerto de referencia del norte peninsular en el comercio del azúcar hasta aproximadamente 1775-1777, fecha en que comenzó a ser desbancado por Santander. Si A Coruña recibió 30.826 arrobas de azúcar en 1768, 103.163 en 1770 y 84.083 en 1773 , seis años más tarde, en 1779, esa cantidad había caído a 29.161, y en 1780 a 1.509. Frente a esta contracción, Santander entraba en una fase de expansión en los inicios de los años setenta. Así, en 1767 se desembarcaban en sus muelles menos de 20.000 arrobas de azúcar, en 1770 unas 25.000, en 1773 en torno a unas 60.000, en 1777 eran ya 83.000 y en 1785 rondaban las 160.000 . Una remontada que en buena medida se explica por la relación preferente que el puerto cántabro consiguió mantener con Cuba y que, a lo largo de la década de 1780, lo convertiría en el principal centro reexpedidor de azúcar del norte de España (Miguel López, 2004, pp. 605-607).

A su nivel, A Coruña también lo fue, al menos hasta unos pocos años antes del fin del monopolio, pues era capaz de atender las necesidades de territorios tan diferentes como Galicia, Asturias, el viejo reino de León o Madrid. Prueba de ello es que el 34,6\% del capital invertido en las compras de azúcar realizadas en su puerto entre 1768 y 1779 estuvieron protagonizadas por agentes comerciales de los Cinco Gremios, conocidos en las fuentes como los «longistas de Madrid», quienes intervenían en el mercado de co- 
loniales coruñés bien directamente o bien por persona interpuesta. En este último caso, casi siempre a través de la figura de Manuel Cerro Rubio, como va dicho, un mercader riojano instalado en A Coruña en 1761, que trabajó como comisionista para los Cinco Gremios comprando azúcar para ellos en el 76,4\% de todas sus operaciones (Tabla 5).

Alrededor de los cueros, el azúcar y un limitadísimo elenco de coloniales giraría la actividad comercial desplegada entre 1768 y 1779 por aproximadamente unos 255 mercaderes, tratantes, negociantes, agentes y particulares, asentados de manera temporal o definitiva en A Coruña (Tabla 4). Aunque, lo cierto, es que el grueso de estas operaciones estuvo controlada por trece personas y una institución foránea, los mencionados Cinco Gremios. Unos y otra responsables del 77,1\% del capital invertido en esos años en la compra de coloniales, la cual se centró básicamente en tres partidas: cueros $(54,1 \%)$, azúcar $(41,1 \%)$ y lana de vicuña $(4,5 \%)$. Estos porcentajes nos recuerdan no solo que este comercio se caracterizaba por concentrarse en unos pocos productos, sino también, que estaba en manos de un reducidísimo número de mercaderes, la mayor parte de ellos foráneos — solo hay un gallego entre ellos - establecidos en la ciudad con posterioridad a la entrada en vigor del Real Decreto de 1765 (Tabla 5). Básicamente, dos razones nos ayudan a entender su enorme relevancia durante el monopolio con América.

Primero, la temprana instalación en A Coruña de una parte de los individuos que conformaban esta minoría de mercaderes y que habría que poner en relación con las oportunidades que en su día les habría ofrecido a futuro, esto es, en términos de capitalización, redes y contactos, la construcción del arsenal de Ferrol. Así, y aunque solo poseemos una información parcial e incompleta sobre la fecha de llegada a la ciudad de esos trece mercaderes, los datos recogidos en la tabla 5 nos permiten apreciar la enorme capacidad de compra que tuvieron aquellos que la habían convertido en su residencia y centro de operaciones con anterioridad a 1765. Al respecto, el vallisoletano Jerónimo Hijosa, el riojano Manuel Cerro Rubio, el asturiano Ramón Fernández de la Barca y el palentino Santiago Diez Tabanera, son responsables de casi las dos terceras partes del capital invertido — en concreto, del 58,1\% del total— en la adquisición de cueros, azúcar y demás productos indianos.

Segundo, y en relación con esto, la tradicional lógica comercial que esos trece mercaderes pusieron en juego a la hora de encarar sus negocios. De ella, da cuenta el hecho de que el 51,6\% de sus tratos se realizasen siempre a beneficio de terceras personas, para las que trabajaban como meros comisionistas o agentes comerciales (Tabla 4). Este tradicionalismo fue sin embargo mucho más acusado en esos cuatro mercaderes llegados a la ciudad antes de 1765, ya que el 69\% de sus compras las hicieron en su condición de comisionistas; porcentaje, curiosamente, que en los otros nueve mercaderes presentes en la tabla 5 se reduce solo a un $35 \%$ del total. En el comportamiento de los primeros podría haber influido el peso de las viejas fórmulas 
Tabla 4. Comerciantes, capital invertido y operaciones realizadas a cuenta de terceros en el mercado de coloniales de A Coruña, 1768-1779

\begin{tabular}{|l|c|c|c|c|}
\hline Inversión en miles rsv. & $\begin{array}{c}\text { Comerciantes } \\
\text { (en \%) }\end{array}$ & $\begin{array}{c}\text { Capital } \\
\text { invertido }\end{array}$ & $\begin{array}{c}\text { \% Capital } \\
\text { invertido }\end{array}$ & $\begin{array}{c}\text { \% operaciones a cuenta } \\
\text { de 30 }\end{array}$ \\
\hline Más de 500 & 5,5 & 32.514 .979 & 77,1 & 51,6 \\
\hline De 100 a 499 & 10,2 & 5.122 .565 & 12,1 & 30,7 \\
\hline De 15 a 99 & 40,0 & 3.717 .081 & 8,8 & 25,8 \\
\hline Menos de 15 & 44,3 & 839.622 & 2,0 & 26,5 \\
\hline Total & 100 & 42.267 .270 & 100 & 40,3 \\
\hline Número de casos & 255 & & & \\
\hline
\end{tabular}

Fuente: ARG, Real Audiencia, leg. 25451-29. Elaboración propia.

Tabla 5. Principales inversores en el comercio de importación de coloniales, 1768-1779

\begin{tabular}{|l|l|c|c|c|c|}
\hline Comprador & $\begin{array}{c}\text { Origen } \\
\text { geográfico }\end{array}$ & $\begin{array}{c}\text { Llegada a la } \\
\text { ciudad }\end{array}$ & $\begin{array}{c}\text { Capital } \\
\text { invertido }\end{array}$ & $\%$ & $\begin{array}{c}\text { \% operaciones a } \\
\text { cuenta de 30 }\end{array}$ \\
\hline Jerónimo Hijosa & Valladolid & 1752 & $9.018 .615,0$ & 21,4 & 60,2 \\
\hline Manuel Cerro Rubio & La Rioja & 1761 & $7.275 .124,2$ & 17,2 & 86,1 \\
\hline Juan Reguera & Asturias & & $2.426 .974,9$ & 5,8 & 51,6 \\
\hline José A. de Llano & País Vasco & 1770 & $2.252 .356,4$ & 5,3 & 22,7 \\
\hline Longistas de Madrid & Madrid & & $2.171 .180,0$ & 5,1 & 0,0 \\
\hline Ramón Fernández de la Barca & Asturias & 1760 & $1.978 .659,6$ & 4,7 & 73,9 \\
\hline Pedro de Llano & País Vasco & 1770 & $1.304 .086,6$ & 3,1 & 8,3 \\
\hline Francisco Pose Rioboo & Galicia & & $1.218 .489,6$ & 2,9 & 75,7 \\
\hline Pedro Pérez Tapia & Asturias & & $1.048 .160,0$ & 2,5 & 100,0 \\
\hline Manuel Monje & Castellano & & $1.044 .000,0$ & 2,5 & 50,0 \\
\hline Lorenzo Llorente & La Rioja & & $767.956,2$ & 1,8 & 4,5 \\
\hline Francisco Placies & Cataluña & & $730.296,0$ & 1,7 & 5,4 \\
\hline Nicolás Poza Merino & & & $639.682,4$ & 1,5 & 18,2 \\
\hline Santiago Diez Tabanera & Palencia & 1760 & $639.397,8$ & 1,5 & 8,3 \\
\hline Total & & & $32.514 .978,7$ & 77,1 & 51,6 \\
\hline
\end{tabular}

Fuente: ARG, Real Audiencia, leg. 25451-29, elaboración propia. Para las fechas de llegada, véase García López, 2008.

comerciales, visto el origen hidalgo de alguno de ellos o que en los años anteriores a 1765 solían especular con granos importados en tiempos de carestía, invertir en arriendos y arbitrios municipales, trabajar como asentistas para la Real Armada o la Real Hacienda - a las que colocaban los productos de sus respectivos lugares de origen: lienzos asturianos, lana leonesa y riojana, aguardiente, vino e indianas catalanas...etc. En estas condiciones, a priori, nada indica que estos individuos fuesen capaces de desarrollar a medio plazo una estrategia comercial que fuese más allá de medrar al amparo de los privilegios que otorgaba el monopolio (Alonso Álvarez, 1986, pp. 62-65; Meijide Pardo, 1967, pp. 90-95). Ahora bien, tampoco parece que la integración en su seno de nuevos mercaderes tras 1765 contribuyese a cambiar mucho esta realidad. Al contrario, las investigaciones realizadas en su día sobre el particular apuntan a que 
ni unos ni otros fueron capaces de poner en pie una flota comercial propia y, menos aún, de desarrollar fórmulas de negocio y mecanismos de pago que les ayudasen a dejar atrás sus viejas prácticas comerciales hasta bien entrada la década de 1780 (Rodríguez Varela, 1977, pp. 307-309; Alonso Álvarez, 1986, pp. 197-202; Cebreiro Ares, 2018, pp. 295-298). Ante esto, no resulta arriesgado afirmar que la elite del comercio colonial asentada en A Coruña encaró el negocio americano con una visión muy tradicional, limitada y cortoplacista.

Por debajo de esta reducida elite, el número de mercaderes, tratantes, negociantes y particulares que intervinieron en el mercado de coloniales corunés aumenta paulatinamente a medida que vamos de los segmentos medio-altos de su comercio a los niveles más bajos del mismo, al tiempo que, y en paralelo, las partidas de dinero que unos y otros invierten en la compra de géneros ultramarinos se reducen (Tabla 4). Curiosamente, en este viaje de la cúspide a la base se reducen también, y mucho, el número de tratos que unos y otros cierran como comisionistas, señal inequívoca de que los contingentes de comerciantes llegados a la ciudad con posterioridad a $1765 \mathrm{se}$ preocuparon más por atender sus propios negocios que de aprovechar las oportunidades que éstos les ofrecían a beneficio de terceros, lo que solo hicieron en un 25-26\% de las ocasiones. Algo que incluso ocurría entre los pequeños compradores de géneros, el $44,3 \%$ del total, responsables solo del $2 \%$ del capital empleado en estas transacciones (Tabla 4). En su caso, muchos de ellos eran particulares, pasajeros o miembros de las tripulaciones de los barcos correo. Gentes como Antonio Moreno, marinero en el Tucumán, arribado a la ensenada coruñesa en 1769 con carga de Montevideo, quien se hizo con 150 cueros al pelo por un valor estimado de 7.830 reales, o como Gabriel Magadán, del que nada sabemos, pero que en 1773 compraba 28 arrobas de azúcar blanco por un valor aproximado de 1.120 reales $^{14}$. La presencia de ambos en los muelles nos indica que este mercado era relativamente abierto. Además, con el paso del tiempo, todo apunta a que tendió a ampliarse, tal y como se deduce de comparar el número de personas que trajinaron en él en 1770, unas 65 , y en 1779, unas 94, lo que supone un incremento entre ambas fechas del $30 \%$.

Durante la época del monopolio muchos mercaderes y negociantes se acercaron hasta A Coruña desde Asturias, el País Vasco, la montaña cántabra, la Rioja, CastillaLeón, Cataluña o el extranjero, con la intención de aprovechar las oportunidades que ofrecían los tráficos americanos (Tabla 6) ${ }^{15}$. Sin embargo, una vez asentados en la

ARG, Real Audiencia, leg. 25451-29, $3^{\text {a }}$ pieza, respectivamente, pgs. 16 y 80.

Quiero a agradecer a Luis Alonso Álvarez toda la información y orientaciones que me proporcionó durante la realización del trabajo, así como a José Manuel Vázquez Lijó, quien puso a mi disposición de una manera generosa y harto desinteresada información documental relativa a las tripulaciones de los correos marítimos depositada en el Archivo General de Indias. 
ciudad no todos los grupos de comerciantes foráneos tuvieron la misma capacidad y posibilidades de cerrar tratos, visto que, y para los años de los que disponemos de información, la inversión que cada uno de ellos realizó en el mercado de coloniales fue muy diferente, lo que, en líneas generales, no parece haber afectado demasiado a sus respectivas estrategias de compra, las cuales, salvo en el caso de vascos y franceses, fueron muy similares entre sí (Tabla 6).

A la cabeza de todos ellos, se encontraban los mercaderes de origen castellano. Poco numerosos, apenas si fueron el 4,7\% de esas 255 personas a las que hemos aludido, demuestran en cambio haber poseído una enorme facilidad para movilizar importantes sumas de dinero en sus operaciones, como se deprende de lo que supone el monto de capital que invirtieron en coloniales (el 51,3\% del total). Su interés se centró sobre todo en la adquisición de cueros al pelo y azúcar, productos que acapararon el 99,2\% de sus compras, la mitad de las cuales, el 51,7\%, fueron realizadas a cuenta de terceras personas. Por debajo estaban los comerciantes asturianos, el 7,5\% del total, cuya capacidad de generar negocio, sea en términos absolutos sea en términos relativos, fue tres veces inferior a la de los anteriores, si bien, y a semejanza de ellos, el 96\% del capital que pusieron en juego se orientó hacia los cueros y el azúcar, actuando como comisionistas en el 48,7\% de las operaciones que llevaron a cabo.

Tabla 6. Procedencia geográfica de los mercaderes, tratantes y particulares involucrados en la compra de coloniales, 1768-1779

\begin{tabular}{|l|c|c|}
\hline Procendencia & Procedencia geográfica & Capital invertido \\
\hline Rioja-Castilla & 4,7 & 51,3 \\
\hline Asturias & 7,5 & 14,8 \\
\hline País Vasco & 17,6 & 14,6 \\
\hline Galicia & 7,5 & 4,5 \\
\hline Cataluña & 6,7 & 4,2 \\
\hline Extranjeros & 1,6 & 1,3 \\
\hline Desconocidos & 54,5 & 9,3 \\
\hline Total & 100 & 100 \\
\hline N.c. & 255 & 42.194 .246 \\
\hline
\end{tabular}

Fuente: ARG, Real Audiencia, leg. 25451-29. Elaboración propia.

En orden de importancia seguían los vascos. El grupo foráneo más nutrido, un $17,6 \%$ del total. Es decir, fueron dos veces más numerosos que los comerciantes asturianos, gallegos o catalanes, y hasta tres veces más que los castellanos (Tabla 6). Ahora bien, frente a todos ellos, el 58\% de sus integrantes formaban o habían formado parte de las tripulaciones de los correos marítimos. El monto total que emplearon en la adquisición de coloniales es muy semejante al de los comerciantes asturianos, no así el interés que mostraron por las diferentes partidas en juego, que tiende a repartirse de 
una manera más o menos equilibrada entre los cueros (37,6\%), el azúcar (37,5\%) y la lana de vicuña $(23,3 \%)$, muy demandada en los mercados franceses y europeos, y a los que los vascos tenían fácil acceso (Pérez García, 2016, p. 194). Su escasa propensión a actuar como agentes a cuenta de terceros en sus tratos, registrada solo en un $21,5 \%$ de las ocasiones, quizás se deba a esa elevada presencia de individuos vinculados a los correos marítimos, una parte significativa de ellos, como luego veremos, capitanes y pilotos, cuya tendencia a actuar como agentes comerciales para los mercaderes bilbaínos y donostiarras, así como a realizar negocios particulares a espaldas de la Renta del Correo, son bien conocidas (Lamikiz, 2008, pp. 94-97; Vázquez Lijó, 2015, pp. 233-234).

En orden de importancia, venían luego los mercaderes gallegos y catalanes, situados ambos al mismo nivel, sea en cuanto a su importancia numérica (respectivamente, un 7,5\% y un 6,7\% del total), o a su capacidad inversora (responsable, respectivamente, del 4,2\% y el 4,5\% del capital invertido en coloniales). Una capacidad esta última, y para que nos hagamos una idea, que resulta ser once veces inferior a la de los comerciantes castellanos y tres veces más baja que la de los asturianos y vascos (Tabla 6). Las similitudes entre gallegos y catalanes se ponen otra vez más de manifiesto en el exacerbado interés que mostraron por la compra de azúcar (respectivamente, $76,5 \%$ y $73,1 \%$ de los desembolsos totales), y su franca propensión a trabajar como comisionistas, en una de cada dos ocasiones, asemejándose en esto a los mencionados castellanos y asturianos (Tabla 6).

En la base de esta jerarquía comercial se disponían los mercaderes extranjeros: básicamente franceses; muy poco numerosos, solo el 1,3\% del total; muy interesados en la adquisición de azúcar, al que dedicaron el 83,3\% de sus inversiones; y poco o nada inclinados a cerrar negocios a comisión.

Los mercaderes castellanos, asturianos, vascos, gallegos, catalanes y franceses, asentados de manera temporal o definitiva en A Coruña, constituyeron un colectivo formado por unas 116 personas, el cual, en los años venideros, se convertirá en la elite que estará a la cabeza de la estructura comercial que ahora se estaba gestando en el noroeste de Galicia. Un número que, en esencia, se mantuvo más o menos estable tras el monopolio —-1768-79: 116, 1778-1803: 127—, a pesar de la continua renovación interna a la que dicho colectivo se vio sometido a causa de la marcha de unos y la llegada de otros (Alonso Álvarez, 2011, p. 58).

Por último, presentes también en el mercado de coloniales encontramos a un importante número de individuos, el 54,5\% del total, del que a día de hoy desconocemos todo lo relativo a su procedencia geográfica, si bien, y a tenor de sus apellidos -Maxoi, Leis, Marín, Beriña, Reigadas, etc.- - entre ellos debía haber no pocos gallegos (Tabla 6). Cierto que una futura identificación de estos pequeños compradores anónimos, realizada mediante un laborioso cruce de información nominativa obtenida 
en fuentes de la más diversa naturaleza podría llegar a alterar el peso relativo de los distintos grupos foráneos que hemos conseguido identificar, pero no lo es menos que el escaso monto de las partidas de dinero que pusieron en juego — un 9,3\% del total—, y su tendencia a realizar una única operación comercial —en el 67\% de las ocasiones-, los alejarían de esa elite mercantil a la que nos hemos referido, además de remitirnos al posible origen local de muchos de ellos. Así parece querer indicárnoslo la aparición en este grupo de individuos como Diego Antonio Cornide, quizás la misma persona que un oidor de la Real Audiencia de Galicia que en esos años vivía en A Coruña, quien en 1773 adquiría 30 arrobas de azúcar blanco y 29 de cacao del Magallanes por 5.361 reales. Su presencia, como la de Juan Antonio Folgueira, pongamos por caso, que en 1779 compra a cuenta de su padre, Lorenzo Folgueira, 16 arrobas de azúcar blanco de la carga del Colón por 640 reales, insisten en el hecho de que el mercado de coloniales no era un coto cerrado, exclusivo, para unos pocos y poderosos, sino que estaba relativamente abierto desde un punto de vista social, por lo que muchos podían llegar a participar en él.

\section{Los tripulantes de los correos marítimos en el mercado de coloniales}

Una de las características más llamativas de este mercado durante la época del monopolio es el protagonismo que en él tuvieron los tripulantes de los correos marítimos, visto que entre 1768 y 1779 fueron el 24\% de todos los individuos que cerraron una operación comercial en su seno (Tabla 5). Es más, una vez rematado dicho monopolio, algunos de ellos llegarían a convertirse en destacados mercaderes locales (Alonso Álvarez, 1986, pp. 173-196).

Sus actividades supusieron la inversión del 7,3\% del capital empleado en pagar los diferentes tratos realizados en la ciudad en esos años, los cuales se centraron en la adquisición de azúcar $(65,4 \%$ del total), cueros (31,3\% del total), y cacao, café, pimienta, palo tinte y otros géneros ultramarinos $(3,3 \% \text { del total })^{16}$. Estas adquisiciones, y a tenor de los registros individuales extractados de la fuente, habrían sido realizadas en el $86 \%$ de las ocasiones por cuenta propia. Sin embargo, esta cifra estaría fuera de la realidad, ya que todo apunta a que es resultado de una importante ocultación efectuada por los interesados. Piénsese que a finales del siglo XVIII el salario medio de un capitán rondaba los 900 reales al mes y el de los pilotos oscilaba entre los 540 y los 600 reales, dos categorías laborales que como puede comprobarse en la tabla 7 fueron el 75,4\% de los compradores y desembolsaron el 93,2\% del capital invertido

\footnotetext{
16 De este cálculo se han excluido los ingresos que los miembros de las tripulaciones consiguieron una vez que dejaron de lado el servicio en la Real Renta del Correo.
} 
por las tripulaciones de los barcos correo en el mercado de coloniales. Y aunque es cierto que las dotaciones de los paquebotes completaban sus ingresos con actividades mercantiles, muchas de ellas fraudulentas a los ojos de la Real Hacienda (Vázquez Lijó, 2015, pp. 233-235), la suma de sus salarios y de aquello que capitanes y pilotos podían llegar a sacar con dichas actividades, no justifica ni explica el monto económico de las operaciones que aparecen registradas a su nombre.

Sin ir más lejos, José Antonio de Llano, por ejemplo, que llegaría a ser uno de los principales comerciantes de coloniales coruñés y, según todos los indicios, casado e instalado en la ciudad hacia 1770 (García López, 2008, pp. 221-223), aparece en 1768-1769 inscrito en los registros de la aduana como piloto del paquebote Pizarro cerrando operaciones en puerto por el equivalente a 187.164 reales. En todos y cada uno de los distintos tratos realizados durante ese bienio, el mencionado José Antonio solo reconoce haber adquirido 611 arrobas de azúcar blanco y quebrado a cuenta del comerciante asturiano Ramón Fernández de la Barca por valor de 24.400 reales. En 1770 nuestro hombre aparece en la documentación como capitán del Quiros, y entre ese año y 1771 realiza negocios por un montante aproximado de 319.998 reales, de los cuales 27.000 provienen de dos operaciones hechas a beneficio del también comerciante Nicolas Pozo Merino (Tabla 5). Como vemos, y fuera de estas dos declaraciones puntuales, un oficial de los correos marítimos que ganaba entre 600 y 900 reales no indica nunca quien fue la persona que le proporcionó el dinero para llevar a cabo unas transacciones cuyo coste final, en el primero de los casos, multiplicaba por 26 su salario anual como piloto y, en el segundo, por 30 el que percibía como capitán.

No obstante, este proceder cambia toda vez que comienza a dejar de lado la navegación en la carrera de Indias, ya que en 1772, 1773 y 1779 encontraremos a José Antonio de Llano invirtiendo un total de 1.824.188 reales en el mercado de coloniales, bien solo o bien en compañía de uno o más socios. A diferencia de lo ocurrido en los años anteriores, reconoce ahora haber realizado compras a cuenta de nueve comerciantes, cuatro de ellos de origen vasco, por un montante de 1.235 .582 reales, es decir, por el $67,7 \%$ del capital empleado en sus tratos. Entre esos comerciantes vascos destacan Lorenzo Beristain, para el que adquiere 20.000 cueros al pelo por un valor aproximado de 1.044.000 reales, o Antonio Ibarrola, a quien asegura 1.169 cueros y 711 arrobas de azúcar blanco y quebrado tras pagar 81.942 reales. Son cantidades respetables que, sin embargo, no le llevaron a despreciar encargos menores, como el efectuado en 1779 por Juan Llano Ibarra, vecino de Bilbao, para quien compró 173 arrobas de azúcar de distintas calidades por 6.940 reales.

Las diferencias de comportamiento que nuestro protagonista muestra antes y después de su vinculación con la Renta del Correo son evidentes y apuntan, tal y como ya se ha señalado, a que muchos capitanes y pilotos habrían funcionado, sobre todo 
si eran vascos - y un 62\% de los capitanes y pilotos aparecidos en la documentación manejada lo eran-, como agentes comerciales para los mercaderes que operaban en tierra, además de aprovechar su categoría y condición profesional para realizar negocios particulares, algunos de ellos más o menos fraudulentos, e incluso ilícitos, a espaldas de la Real Hacienda (Lamikiz, 2008, pp. 94-100; Vázquez Lijó, 2015, pp. 233-235). Quizás sorprenda el potencial nivel de fraude detectado en las operaciones de José Antonio de Llano durante el tiempo que estuvo enrolado en los barcos correo, o cuando menos la ocultación sistemática del nombre de las personas a favor de quienes cerraba los tratos, pero lo cierto es que no debería hacerlo. A fin de cuentas, el memorial de registros que constituye la base de este trabajo sale a la luz por el impago, por el fraude, cometido por los hombres del comercio de la ciudad, quienes durante los años que duró el monopolio con América evitaron hacer frente al pago de los derechos de peso y portazgo de las mercancías entradas en puerto.

Tabla 7. Inversiones de la tripulación involucrada en la compra de coloniales, 1768-1779

\begin{tabular}{|l|c|c|c|}
\hline Categoría & Número & Capital invertido & $\begin{array}{c}\text { \% operaciones a } \\
\text { cuenta de 30 }\end{array}$ \\
\hline Capitán & 57,4 & 77,5 & 14,1 \\
\hline Piloto & 18,0 & 15,7 & 17,5 \\
\hline Cirujano & 4,9 & 3,1 & 20,0 \\
\hline Contramaestre & 8,2 & 1,7 & 0,0 \\
\hline Marinero & 9,8 & 1,7 & 0,0 \\
\hline Artillero & 1,6 & 0,2 & 0,0 \\
\hline Total & 100 & 100 & 13,5 \\
\hline N.c. & 61 & $3.218 .344,8$ & \\
\hline
\end{tabular}

Fuente: ARG, Real Audiencia, leg. 25451-29. Elaboración propia.

Pero este patrón de comportamiento no era exclusivo de capitanes y oficiales. A su nivel, podemos encontrarlo también reproducido en el resto de las dotaciones de los barcos correo. Por ejemplo, Ignacio Manzanares, contramaestre de origen gallego en el Colón, cuyo salario mensual rondaba los 360 reales, cerraba en 1771 y 1772 la compra de varios cientos de arrobas de azúcar por 14.520 reales, mientras que en 1779 el marinero de la fragata Diana, Pedro García, a su vez de origen gallego y con unos ingresos salariales de 150 reales al mes, adquiría 220 cueros al pelo por 11.484 reales. Es decir, y para entendernos, ambos realizaban operaciones por cantidades que multiplicaban por 3,4 y 6,4 sus respectivos salarios anuales sin indicar nunca a favor de quien las hacían, al igual que, y por citar un caso más, Francisco Rioboo, contramaestre de la Tucumán, quien compraba a su nombre 10.000 libras de sebo negro en 1769. Ahora bien, aunque el citado patrón de comportamiento sea el mismo en toda la escala de empleados en los correos marítimos, no lo eran en cambio sus estrategias 
de compra. Por ejemplo, el grupo formado por los contramaestres parece haber optado por adquirir azúcar, al que dedicaron el 90,1\% del total de sus inversiones, mientras que el de los cirujanos y la marinería preferían los cueros al pelo, a los que destinaron, respectivamente, el 100\% y el 69,3\% de lo que gastaron en el mercado coruñés.

De manera parecida a como sucedía con los comerciantes, entre las dotaciones de los paquebotes también es posible advertir la existencia de una jerarquía interna en función del desigual alcance de las operaciones realizadas, el cual, por otra parte, guarda una cierta relación con el origen geográfico de los compradores. Conforme a ello, a la cabeza de esta jerarquía se encuentran los vascos, el $42 \%$ de los tripulantes que aparecen comprando coloniales, quienes en ocho de cada diez ocasiones demuestran ser capitanes y en el resto pilotos y pilotines, si bien, todos ellos responsables del $66,5 \%$ de los desembolsos efectuados por los integrantes de dichas dotaciones entre 1768 y 1779 . En importancia seguían los gallegos, el 9,8\% del total, entre los que abundan los individuos pertenecientes a las escalas intermedias y bajas — pilotos, contramaestres, cirujanos, artilleros y marineros - , cuya capacidad para negociar con los géneros ultramarinos era por tanto sensiblemente inferior a la de los anteriores, visto que solo fueron responsables del 3,4\% del capital puesto en juego. Aunque menor importancia tuvieron los tripulantes de origen asturiano, 4,9\% del total, o cántabro, $1,6 \%$ del total, pues el costo de sus adquisiciones, en origen o en el puerto corunés, fue anecdótico, apenas si comparable al de los capitanes, pilotos, contramaestres y marineros de los que no nos ha sido posible establecer su procedencia geográfica, el $41 \%$ del total. En todo caso, de estos últimos sabemos que, en conjunto, su capacidad de negocio era muy inferior a la de los vascos, ya que solo fueron responsables del $27,9 \%$ de las partidas monetarias invertidas.

\section{Conclusiones}

Durante la primera mitad del siglo XVIII, las continuas arribadas de plata americana a los puertos gallegos y el inicio de la construcción de arsenal de Ferrol sentaron la base de los cambios que iban a producirse en el seno de la tradicional estructura comercial que existía en el noroeste de Galicia. En sus niveles más elevados, se produjo la paulatina llegada e integración de un reducido grupo de mercaderes foráneos, el grueso de los cuales comenzó a asentarse de manera definitiva en A Coruña a partir de 1750. En un contexto marcado por esta serie de lentas transformaciones en el plano comercial, la habilitación de su puerto en 1765 para comerciar con América en régimen de monopolio contribuyó a acelerarlas, propiciando así la arribada a la ciudad de más mercaderes, negociantes y tratantes desde los más variados puntos del norte de España, interesados en los cargamentos de plata y coloniales. Estos últimos, dieron 
vida a un mercado muy poco diversificado, centrado en poco más de media docena de productos, entre los que destacaban los cueros rioplatenses y el azúcar cubano; unos géneros sobre los que A Coruña asentó su primacía comercial como principal puerto reexportador de coloniales del norte de España hasta 1778, si bien, en el caso del azúcar esa primacía comenzó a ser cuestionada por Santander ya a comienzos de la década de 1770 .

En torno a estos productos ultramarinos giró la actividad de una reducida elite comercial, compuesta por apenas un centenar de personas de distinta procedencia, dentro de la cual reinaban sin oposición media docena de mercaderes. Éstos, controlaban el grueso del comercio realizado por esa elite, al tiempo que se distinguían del resto de sus componentes tanto por haberse instalado la ciudad con anterioridad a 1765 como por el marcado carácter tradicional de sus tratos. Un tradicionalismo que, a este nivel, y si usamos como indicador el número de operaciones efectuadas a cuenta de terceros, sería menos acusado entre los comerciantes asentados en A Coruña tras 1765 y entre aquellos que operaban en los sectores medios y bajos del comercio americano. Por otro lado, es precisamente la actividad de esos sectores bajos la que nos indica, a través de sus intervenciones puntuales, que el mercado de coloniales se caracterizó asimismo por su relativa apertura social, vista, por ejemplo, la participación en él de personajes anónimos y tripulantes de los correos marítimos pertenecientes a sus distintas escalas laborales, quienes con su actividad ponen de manifiesto el elevado nivel de fraude que se daba en el mismo.

En suma, el comercio de coloniales realizado a través del puerto de A Coruña durante la época del monopolio nos permite asistir, entre otras cosas, al proceso que condujo a la configuración de una élite mercantil que, tras la aprobación de los Decretos de Libre Comercio, quedaría situada a la cabeza de la estructura comercial gestada en el noroeste de Galicia desde aproximadamente 1730-1740. También nos permite entrever los efectos comerciales e industriales que se derivaron de ese complejo proceso de gestación, los cuales, sin embargo, se manifestaron en toda su amplitud con posterioridad a 1778 (Alonso Álvarez, 1986, pp. 68 y ss.; Carmona, 1990, pp. 68-72; ID., 2003, pp. 26-36). Pero esa, es ya otra historia. 


\section{Bibliografía}

Alonso Álvarez, Luis Alonso (1977), Industrialización y conflictos sociales en la Galicia del Antiguo Régimen, 1750-1830, Madrid, Editorial Akal.

Alonso Álvarez, Luis Alonso (1986), Comercio colonial y crisis del Antiguo Régimen en Galicia (1778-1818), A Coruña, Xunta de Galicia.

Alonso Álvarez, Luis Alonso (1991), "Especialización mercantil y crisis de la economía rural. Las importaciones coloniales durante la época del Libre Comercio, 1778-1816", Anuario de Estudios Americanos, 48, pp. 463-478.

Alonso Álvarez, Luis Alonso (2011), "La sociedad de los correos marítimos y sus encadenamientos empresariales en las economías cantábricas, 1764-1802", en Ocampo Suárez-Valdés, Joaquin (ed.), Empresas y empresarios en el norte de España, siglo XVIII, Gijón Nigra-Trea, pp. 39-69.

Aragon RuAnO, Álvaro (2017), “"Mar de árboles, vorágine de jurisdicciones'. La complicada relación entre la Real Armada y los bosques del Pirineo occidental peninsular en el siglo XVIII”, en Varela Gomes, Rosa y Trápaga Monchet, Koldo, Árvores, barcos e homens na Península Ibérica, séculos XVI-XVIII, Navarra, Ulzama Digital, pp. 41-55.

Belloto, Manoel L. (1971), Comercio Marítimo Hispano-Americano. A Carreira de Buenos Aires, 1767-1779, Assis, Facultade de Filosofía, Ciências e Letras de Assis.

Carmona Badía, Xoán (1990), El atraso industrial de Galicia. Auge y liquidación de las manufacturas textiles, 1750-1900, Barcelona, Ariel.

Carmona Badía, Xoán (2003), A Compostela industrial. Historia e pegada das fábricas de coiros no concello de Santiago, Santiago de Compostela, Consorcio de Santiago.

Cebreiro Ares, Francisco (2017), Circulación monetaria y crédito en Galicia al final del Antiguo Régimen, Tesis Doctoral Inédita, Universidad de Santiago, 1.048 pgs.

Cuesta, Martín (2007), "Precios y mercados en Buenos Aires en el siglo XVIII", América Latina en la Historia Económica, 28, pp. 27-57. https://doi.org/10.18232/ alhe.v14i2.314

Dubert, Isidro (2008), “Comercio y tráfico marítimo en la Galicia del Antiguo Régimen, 1750-1820”, Obradoiro de Historia Moderna, 17, pp. 211-243.

DuBERT, Isidro (2009), "Evolución y estructura del comercio marítimo del sudoeste gallego a finales del Antiguo Régimen, 1796-1816", en Dubert, Isidro y Sobrado, Hortensio (eds.), El mar en los siglos modernos, Betanzos, Xunta de Galicia, vol. 1, pp. 379-395.

Ferreira Priegue, Elisa (1988), Galicia en el comercio marítimo medieval, A Coruña, Fundación Pedro Barrié de la Maza. 
Ferreira Priegue, Elisa (2000), "La villa de Pontevedra y el comercio de Galicia en la primera mitad del siglo XVI", en Eiras Roel, Antonio (ed.), El reino de Galicia en la época del emperador Carlos V, Santiago de Compostela, Xunta de Galicia, pp. 581-606.

García Lombardero, Xaime, Carmona, Joam (1985), “Tradición e modernización nas pescarías galegas. Artes de pesca e organización da producción, (séculos XVIII-XIX)", Actas do Coloquio "Santos Graça” de Etnografía Marítima, vol. 2, Cámara Municipal de Povoa do Barzim, pp. 27-45.

García-Baquero GonzÁlez, Antonio (1998), Cádiz y el Atlántico (1717-1778). El comercio colonial español bajo el monopolio gaditano, Cádiz, Diputación Provincial de Cádiz, 2 vols.

García LóPez, Alfonso (2008), Los pioneros del comercio en A Coruña, Valladolid, Editorial Lex Nova.

GonzÁlez Fernández, Juan M. y Tizón Rodríguez, José A. (2003), “La burguesía mercantil viguesa del siglo XVIII. Aspectos sociales (1)”, Boletín del Instituto de Estudios Vigueses, 9, pp. 65-92.

Juega Puig, Juan (2014), El comercio marítimo de Galicia, 1525-1640, Pontevedra, Deputación de Pontevedra.

LAMIKIZ, Xavier (2016), "Basque shipcaptains as mariners and traders in the Eighteenth Century”, International Journal of Maritime History, 2, pp. 81-109.

LANZA GARCíA, Ramón (2006), "El puerto de Santander en el siglo XVIII: entre el privilegio y la libertad de comercio", en Fortea, José I. y Gelabert, Juan E. (eds.), La ciudad portuaria atlántica en la historia, siglos XVI-XIX, Santander, Universidad de Cantabria, pp. 413-449.

Martín GarcíA, Alfredo (2003), Una sociedad en cambio. Ferrol a finales del Antiguo Régimen, Ferrol, Edicións Embora.

Meijide PARdo, Antonio (1967), "Hombres de negocio en la Coruña diceiochesca: Jerónimo Hijosa", Revista del Instituto José Cornide de Estudios Coruñeses, 3 , pp. 85-148.

Meijide PARdo, Antonio (1973), “Aspectos del comercio gallego de exportación a Portugal en el siglo XVIII", Actas de las I Jornadas de Metodología Histórica Aplicada, Santiago, Universidade de Santiago, t. 1, pp. 803-823.

Meijide PARdo, Antonio (1976), "Negociantes franceses de La Coruña. M. de Lagoanere y Cia.”, Revista del Instituto José Cornide de A Coruña, 12, pp. 207-224.

MeIJide PARdo, Antonio (1984a), El puerto de La Coruña en el siglo XVIII, A Coruña, La Voz de Galicia.

Meijide PARdo, Antonio (1984b), “La penetración económica catalana en el puerto gallego de Mugardos”, Pedralbes. Revista d'Història Moderna, 4, pp. 7-39. 
Meijide PARdo, Antonio (1990), Correos maritimos entre Falmouth y A Coruña (16891815), A Coruña, Liberia Arenas.

Miguel LóPEZ, Isabel (2004), "Santander: redistribuidor euroamericano de mercancías (1766-1785)", Hispania, 54/2, 217, pp. 601-636. https://doi.org/10.3989/ hispania.2004.v64.i217.189

Moreno Fraginals, Manuel (2001), El Ingenio, complejo económico-social cubano del azúcar, Barcelona, Editorial Crítica.

PÉRez GARCÍA, Manuel (2016), “Mercados globales de la América española: el comercio de lana de vicuña y grana de Cochinilla en el siglo XVIII", América Latina en la Historia Económica, 23, pp. 184-222. https://doi.org/10.18232/alhe.v23i1.68

Rodríguez VARELA, Elisa (1977), "El Real Consulado de Comercio de La Coruña y la apertura del comercio indiano", en Eiras Roel et al., Las fuentes y los métodos. 15 trabajos de Historia Cuantitativa Serial de Galicia, Santiago, Universidade de Santiago de Compostela, pp. 307-323.

Rubio PÉREZ, Laureano (1995), La burguesía maragata. Dimensión social, comercio y capital en la Corona de Castilla durante la Edad Moderna, León, Universidad de León.

Silva, Hernán A. (1993), El comercio entre España y el Río de la Plata, 1778-1810, Madrid, Banco de España-Estudios de Historia Económica, 26.

VÁzQuez Lijó, José M. (2015), “Servir en los buques correo: oportunidades laborales en A Coruña, 1764-1802”, en Rey Castelao, Ofelia y Mantecón, Tomás (eds.), Identidades urbanas en la monarquía hispana, siglos XVI-XVIII, Santiago, Universidade de Santiago de Compostela, pp. 213-237.

VÁzQuez LiJó, José M. (2016), “Una panorámica de la flota gallega, 1752-1802”, Minius, 4, pp. 77-110.

VÁzQuez LiJó, José M. (2017), "El corso gallego en la Guerra del Asiento (1739-1748): escenarios, actores y presas”, Obradoiro de Historia Moderna, 26, pp. 119-148. https://doi.org/10.15304/ohm.26.4422

Zabala Uriarte, Aingeru (1983), El comercio y el tráfico marítimo del norte de España en el siglo XVIII, Zarautz, Haramburu Editor, 2 vols.

Zabala Uriarte, Aingeru (1986), "La distribución de la actividad comerial en el Cantábrico en torno a los Decretos de Libre Comercio”, en Martínez Vara, Tomás (ed.), Mercado y desarrollo económico en la España contemporánea, Madrid, Siglo XXI, pp. 41-67. 